\title{
Atypical Antipsychotics are Disproportionately Associated with Patients Reporting Increased Eating Drives
}

\author{
Sun Young Yum 1 , Sun Kyoung Yum², and Hyung Jin Choi ${ }^{3 凶}$ \\ ${ }^{1}$ Department of Clinical Medical Sciences, Seoul National University, Seoul, Republic of Korea \\ ${ }^{2}$ Chaum Life Center, CHA University School of Medicine, Seoul, Republic of Korea \\ ${ }^{3}$ Department of Biomedical Sciences, Seoul National University, Seoul, Republic of Korea
}

\section{Dear Editor,}

Patients with schizophrenia have various eating disturbances that are sometimes brought on or worsened by certain medications. ${ }^{1}$ We explored whether atypical antipsychotics increase eating drives by mining a drug adverse event $(\mathrm{AE})$ database.

We mined the US Food and Drug Administration's (FDA's) AE Reporting System (FAERS) using the FAERS Public Dashboard, ${ }^{2}$ which included AE cases reported until September 30, 2020. FAERS data sources include mandatory reporting from manufacturers and distributors as well as independent reporting by consumers and health professionals. Drug-event pairs were extracted using the proprietary names of 5 antipsychotics: Abilify, Geodon, Risperdal, Seroquel, and Zyprexa). Individual $\mathrm{AE}$ terms related to increased eating drive were extracted: hunger, increased appetite, food craving, and their aggregated cluster. The event term hyperphagia was extracted as a behavioral output to see whether it was consistent with increased eating drives.

Among the traditional methods for assessing whether a particular $\mathrm{AE}$ occurs at disproportionately high rates compared to other drugs, we used the reporting odds ratio (ROR). The ROR is the ratio of the odds of reporting of one specific event vs all other events for a given drug compared to the reporting odds for all other drugs present in the database. A drug adverse reaction signal is considered when the lower limit of the $95 \%$ confidence interval (CI) of the ROR exceeds $1 .^{3}$

As the study mined a publically available database with no

Received: December 15, 2020 Revised: December 28, 2020

Accepted: December 29, 2020

$\triangle$ Correspondence: Hyung Jin Choi, MD, PhD

Department of Biomedical Sciences, BK21 Plus Biomedical Science Project Team, Seoul National University College of Medicine, 103 Daehak-ro, Jongno-gu, Seoul 03080, Korea

Tel: +82-2-740-8204, Fax: +82-2-745-9528, E-mail: hjchoi@snu.ac.kr

(9) This is an Open Access article distributed under the terms of the Creative Commons Attribution Non-Commercial License (https://creativecommons.org/licenses/by$\mathrm{nc} / 4.0$ ) which permits unrestricted non-commercial use, distribution, and reproduction in any medium, provided the original work is properly cited. sensitive information, an exemption status was granted from the Institutional Review Board of the Seoul National University Hospital.

Of a total of 20,864,095 AE case reports in the FAERS system, the total AE report counts for the 5 antipsychotics were were 49,463 for aripiprazole, 9,146 for ziprasidone, 59,354 for risperidone, 44,002 for quetiapine, and 33,791 for olanzapine. The frequency of events for each of the AEs extracted and their RORs are presented in Figure 1.

Cluster of increased eating drive was disproportionately reported for all 5 antipsychotics (ORs 7.66-15.39). The order of signal strengths for the eating drives was identical to the behavioral output of hyperphagia, which was also reported at disproportionately high rates for antipsychotics (ORs 6.8535.61). The odds calculated here are against all events from all drugs in the database that have been around for longer than the atypical antipsychotics. If extraction was limited to 5 years postlaunch for each drug, which is when drug AE reports generally peak in frequency, the strength of the signal was likely to be greater.

Whether to include lack of satiety in the cluster was a dilemma. Lack of satiety may or may not increase eating drive or lead to the behavioral output of increased eating. Inability to feel satiated could lead to delayed termination of eating or termination after larger volumes of food are consumed. However, if portion sizes are pre-defined, the amount of food consumed may not be affected. For example, if a person eats a chocolate bar when hungry, the frequency of hunger-not the inability to feel full - will determine food intake. If maintenance of satiety is impaired, this could lead to increase in frequency of hunger, which most patients express as being hungry more frequently rather than lacking satiety. Accordingly, lack of satiety was not included in the AE cluster for increased eating drive. In the end, separate analyses including lack of satiety in the cluster did not alter the direction of the signal; signal strength 


\begin{tabular}{|c|c|c|c|c|c|c|c|}
\hline \multicolumn{8}{|l|}{ 1. Hunger } \\
\hline & \multicolumn{2}{|c|}{ Antipsychotic } & \multicolumn{2}{|c|}{ Other drugs } & \multirow{2}{*}{ ROR $[95 \% \mathrm{CI}]$} & & \\
\hline Drug & Events & Total & Events & Total & & & \\
\hline$\overline{\text { Abilify }}$ & 135 & 49,463 & 6,983 & $20,814,632$ & $8.15[6.88,9.67]$ & & - \\
\hline Geodon & 30 & 9,146 & 7,088 & $20,854,949$ & $9.68[6.76,13.86]$ & & -- \\
\hline Risperdal & 64 & 59,354 & 7,054 & $20,804,741$ & $3.18[2.49,4.07]$ & & $\rightarrow$ \\
\hline Seroquel & 118 & 44,002 & 7,000 & $20,820,093$ & $7.99[6.66,9.59]$ & & $=-$ \\
\hline \multirow[t]{3}{*}{ Zyprexa } & 113 & 33,791 & 7,005 & $20,830,304$ & $9.97[8.28,12.02]$ & & - \\
\hline & & & & & 0.1 & $\begin{array}{lll}0.2 & 0.5 & 1\end{array}$ & $\begin{array}{ccc} & 1 & 1 \\
2 & 5 & 10\end{array}$ \\
\hline & & & & & & $\begin{array}{l}\text { Other drugs } \\
\text { ROR }[9\end{array}$ & $\begin{array}{l}\text { Antipsychotic of interest } \\
5 \% \mathrm{CI}]\end{array}$ \\
\hline \multicolumn{8}{|c|}{ 2. Increased appetite } \\
\hline & \multicolumn{2}{|c|}{ Antipsychotic } & \multicolumn{2}{|c|}{ Other drugs } & & & \\
\hline Drug & Events & Total & Events & Total & ROR $[95 \%$ Cl] & & \\
\hline$\overline{\text { Abilify }}$ & 292 & 49,463 & 13,972 & $20,814,632$ & $8.84[7.87,9.93]$ & & $=$ \\
\hline Geodon & 50 & 9,146 & 14,214 & $20,854,949$ & $8.06[6.10,10.65]$ & & -- \\
\hline Risperdal & 425 & 59,354 & 13,839 & $20,804,741$ & $10.83[9.83,11.94]$ & & = \\
\hline Seroquel & 274 & 44,002 & 13,990 & $20,820,093$ & $9.32[8.27,10.51]$ & & $=$ \\
\hline \multirow[t]{3}{*}{ Zyprexa } & 404 & 33,791 & 13,860 & $20,830,304$ & $18.17[16.45,20.08]$ & & 룰 \\
\hline & & & & & 0.05 & $\begin{array}{ll}0.2 & 1\end{array}$ & $\begin{array}{ll}1 & 20\end{array}$ \\
\hline & & & & & & $\begin{array}{l}\text { Other drugs } \\
\text { ROR }[9\end{array}$ & $\begin{array}{l}\text { Antipsychotic of interest } \\
5 \% \mathrm{CI}]\end{array}$ \\
\hline \multicolumn{8}{|c|}{ 3. Food craving } \\
\hline & \multicolumn{2}{|c|}{ Antipsychotic } & \multicolumn{2}{|c|}{ Other drugs } & & & \\
\hline Drug & Events & Total & Events & Total & RUR [95\% C1] & & \\
\hline$\overline{\text { Abilify }}$ & 69 & 49,463 & 2,402 & $20,814,632$ & $12.10[9.53,15.38]$ & & - \\
\hline Geodon & 7 & 9,146 & 2,464 & $20,854,949$ & $6.48[3.09,13.62]$ & & $=$ \\
\hline Risperdal & 10 & 59,354 & 2,461 & $20,804,741$ & $1.42[0.77,2.65]$ & & $=-$ \\
\hline Seroquel & 83 & 44,002 & 2,388 & $20,820,093$ & $16.47[13.23,20.51]$ & & - \\
\hline \multirow[t]{3}{*}{ Zyprexa } & 84 & 33,791 & 2,387 & $20,830,304$ & $21.74[17.49,27.04]$ & & - \\
\hline & & & & & 0.05 & $\begin{array}{ll}1 & 1\end{array}$ & $\begin{array}{ll} & 1 \\
5 & 20\end{array}$ \\
\hline & & & & & & $\begin{array}{l}\text { Other drugs } \\
\text { ROR }[9\end{array}$ & $\begin{array}{l}\text { Antipsychotic of interest } \\
5 \% \mathrm{CI}]\end{array}$ \\
\hline 4. Increase & ting drive & lunger $+\mathrm{i}$ & ased app & e+craving) & & & \\
\hline & Anti & chotic & & rdrugs & & & \\
\hline Drug & Events & Total & Events & Total & ROR $[95 \%$ Cl] & & \\
\hline$\overline{\text { Abilify }}$ & 462 & 49,463 & 22,795 & $20,814,632$ & $8.60[7.84,9.43]$ & & $=$ \\
\hline Geodon & 84 & 9,146 & 23,173 & $20,854,949$ & $8.33[6.72,10.33]$ & & - \\
\hline Risperdal & 494 & 59,354 & 22,763 & $20,804,741$ & $7.66[7.01,8.38]$ & & - \\
\hline Seroquel & 450 & 44,002 & 22,807 & $20,820,093$ & $9.42[8.58,10.35]$ & & - \\
\hline Zyprexa & 558 & 33,791 & 22,699 & $20,830,304$ & $15.39[14.14,16.75]$ & & 口 \\
\hline & & & & & 0.05 & $0.2 \quad 1$ & $\begin{array}{ll}1 & 1 \\
5 & 20\end{array}$ \\
\hline & & & & & & $\begin{array}{l}\text { Other drugs } \\
\text { ROR }[9\end{array}$ & $\begin{array}{l}\text { Antipsychotic of interest } \\
5 \% \mathrm{CI}]\end{array}$ \\
\hline 5. Hyperpl & a--behavi & output & & & & & \\
\hline & Anti & chotic & & r drugs & & & \\
\hline Drug & Events & Total & Events & Total & $\operatorname{ROR}[95 \% \mathrm{Cl}]$ & & \\
\hline Abilify & 104 & 49,463 & 2,506 & $20,814,632$ & $17.50[14.38,21.29]$ & & $=$ \\
\hline Geodon & 12 & 9,146 & 2,598 & $20,854,949$ & $10.54[5.98,18.60]$ & & $\multimap$ \\
\hline Risperdal & 50 & 59,354 & 2,560 & $20,804,741$ & $6.85[5.18,9.06]$ & & 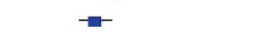 \\
\hline Seroquel & 61 & 44,002 & 2,549 & $20,820,093$ & $11.34[8.79,14.62]$ & & $=$ \\
\hline Zyprexa & 142 & 33,791 & 2,468 & $20,830,304$ & $35.61[30.06,42.19]$ & & $=$ \\
\hline & & & & & 0.02 & $0.1 \quad 1$ & $\begin{array}{ll}10 & 50\end{array}$ \\
\hline & & & & & & $\begin{array}{l}\text { Other drugs } \\
\text { ROR [95 }\end{array}$ & $\begin{array}{l}\text { Antipsychotic of interest } \\
\% \text { CI] }\end{array}$ \\
\hline 6. Lack of & & & & & & & \\
\hline & Anti & chotic & & r drugs & ROR [95\% CI] & & \\
\hline$\underline{\text { Drug }}$ & Events & Total & Events & Total & KUK [95\% CI] & & \\
\hline$\overline{\text { Abilify }}$ & 4 & 49,463 & 103 & $20,814,632$ & $16.34[6.02,44.38]$ & & $\rightarrow-$ \\
\hline Geodon & 0 & 9,146 & 107 & $20,854,949$ & $10.61[0.66,170.66]$ & & $\longrightarrow$ \\
\hline Risperdal & 0 & 59,354 & 107 & $20,804,741$ & $1.63[0.10,26.23]$ & & \\
\hline Seroquel & 1 & 44,002 & 106 & $20,820,093$ & $4.46[0.62,31.98]$ & - & \\
\hline Zyprexa & 2 & 33,791 & 105 & $20,830,304$ & $11.74[2.90,47.57]$ & & $\longrightarrow-$ \\
\hline & & & & & 0.01 & $\begin{array}{ll}1 & 1\end{array}$ & $\begin{array}{ll}10 & 100\end{array}$ \\
\hline & & & & & & $\begin{array}{l}\text { Other drugs } \\
\text { ROR }[95\end{array}$ & $\begin{array}{l}\text { Antipsychotic of interest } \\
\% \text { CI] }\end{array}$ \\
\hline
\end{tabular}

Figure 1. Contingency tables and reporting odds ratios of drug-event pairs for atypical antipsychotics: increased eating drives and behavioral output. 
was not noticeably affected either.

There were subtle differences in the strengths of RORs for each of the event terms for each of the antipsychotics. It may be hypothesized that since antihistamines are well known to induce increased hunger, an antipsychotic with greater antihistaminic properties may be more likely to increase hunger. It may also be hypothesized that the stronger the antidopaminergic properties, the lower the motivational salience associated with food due to reduced ability to feel pleasure, or the greater the food intake to try to achieve the pleasure with increased volumes of food. However, such hypotheses cannot be tested with drug safety big data. Patients on a drug with lower antihistaminic potential may be prescribed higher doses of the medication or concomitant antihistamines, and AE case reports are not likely to contain clinical history in such detail.

It is probably overinterpretation of FAERS mining to try to separate the physiologic signal of hunger and experiences associated with motivational salience such as appetite or craving. Despite their distinct neurobiology, people use the terms hunger, appetite, and craving interchangeably in daily language; thus, spontaneous reporting of these experiences is less likely to be precise.

Comparisons among the antipsychotics from the FAERS is not likely to be useful. Since FAERS is a nonrandom sample, clinical characteristics and underlying psychopathology are likely to have led to the different antipsychotics being selected for individual patients. Also, physician and patient expectations of AEs may influence reporting rates. Some physicians do not report AEs that they expect to occur, while others may only observe and report known AEs that they monitor for during patient follow-ups.

Using safety big data systems still has value, as it allows observation of trends in the real world at a global level for new hypothesis generation. We hope the signals presented will stim- ulate hypotheses generation about the orexigenic or appetitive stimulation potential of antipsychotics as well as further confirmatory research efforts while providing information to assist clinical decision making.

In conclusion, patients taking atypical antipsychotics have disproportionately high rates of reporting increased eating drives and hyperphagia as drug AEs.

\section{Acknowledgments}

None.

\section{Conflicts of Interest}

The authors have no potential conflicts of interest to disclose.

\section{Author Contributions}

Conceptualization: all authors. Data curation: Sun Young Yum. Formal analysis: Sun Young Yum. Funding acquisition: Hyung Jin Choi. Investigation: Sun Young Yum, Sun Kyoung Yum. Methodology: Sun Young Yum, Sun Kyoung Yum. Project administration: Sun Young Yum. Resources: Hyung Jin Choi. Software: Sun Young Yum. Supervision: Hyung Jin Choi. Validation: Sun Kyoung Yum. Visualization: Sun Young Yum. Writingoriginal draft: all authors. Writing—review \& editing: all authors.

\section{ORCID iDs}

Sun Young Yum https://orcid.org/0000-0003-2620-6448

Sun Kyoung Yum https://orcid.org/0000-0003-1153-1934

Hyung Jin Choi https://orcid.org/0000-0003-0593-6978

\section{REFERENCES}

1. Yum SY, Caracci G, Hwang MY. Schizophrenia and eating disorders. Psychiatr Clin North Am 2009;32:809-819.

2. US Food and Drug Administration. FAERS public dashboard. Available at: https://www.fda.gov/drugs/questions-and-answers-fdas-adverse-event-reporting-system-faers/fda-adverse-event-reporting-system-faers-public-dashboard Accessed Dec 11, 2020.

3. Van Puijenbroek EP, Bate A, Leufkens HG, Lindquist M, Orre R, Egberts AC. A comparison of measures of disproportionality for signal detection in spontaneous reporting systems for adverse drug reactions. Pharmacoepidemiol Drug Saf 2002;11:3-10. 